TURIZAM

Volume 23, Issue 3

120-132 (2019)

ORIGINAL

SCIENTIFIC PAPER

\title{
Innovative Service Experiences of Travellers Visiting High-Tech Hotels: The Case of Eccleston Square Hotel, London
}

\author{
Kadir ÇakarA*, Şehmus Aykol ${ }^{\mathrm{A}}$ \\ Received: August 2019 | Accepted: September 2019 \\ DOI: 10.5937/turizam23-22009
}

\begin{abstract}
The purpose of the current qualitative research on travellers' behaviors and attitudes visiting high-tech hotels is to examine and understand the effects of innovative service experiences. With the aim of contributing to knowledge in the field of service research, this paper has employed user-generated content (UGC) within the context of a qualitative research method. Data was obtained from online reviews left by travellers $(n=350)$ on TripAdvisor who visited the Eccleston Square Hotel in London, which generated the unit of data analysis and was processed through content analysis. Findings of the present study have indicated that the innovative service experiences of travellers visiting the Eccleston Square Hotel reflect many heterogeneous and multidimensional features. Results have also revealed that travellers are more disposed towards visiting technologically oriented and equipped hotels that can improve the quality of customer experience while potentially creating a positive impact on their satisfaction levels and intentions to revisit, as well as positive eWOM effects for other travellers.
\end{abstract}

Keywords: Innovative service experiences, Information and communications technologies, Innovation in tourism, Qualitative research, User-generated-content

\section{Introduction}

The tourism and hospitality industry has been considerably affected by rapidly developing technological innovations (Leung, Law, 2007). In particular, after the 1980s, through the rapid advancement of information and communication technologies (ICTs), a remarkable shift in the hospitality and tourism industry has occurred, which, indeed, is still continuing across the globe (Buhalis, Licata, 2002; Buhalis, Law, 2008; Ip et al., 2011; Law et al., 2014).

Over the past twenty-five years, the concept of service innovation has gained considerable attention by a number of scholars (Carlborg et al., 2013) and innovation in the hospitality and tourism industry, unlike product innovation, reflects a different component of service innova-

A Faculty of Tourism Mardin Artuklu University, Mardin, Turkey

* Corresponding author: kadircakar@artuklu.edu.tr 
tion (Gremyr et al., 2014). Such innovation can enhance customer experience by providing new services, such as using a phone as a key card, mobile self-check-in, mobile booking, self-service check-in kiosks, lobby media panels, electronic luggage tags, smartphone boarding passes, hotel service optimization systems, guest device connectivity tools, voiceover internet protocol phones, etc. (Bilgihan, Nejad, 2015; Wang et al., 2014). In the existing literature, ten types of visitor experiences have been originally identified and described, namely, physical, restorative, sensory, introspective, cognitive, transformative, emotional, spiritual, hedonic and relational (Packer, Ballantyne, 2016).

However, in the existing hospitality and tourism literature, there has been a limited amount of research carried out addressing the issue of service innovation experience from the perspective of ICTs, based on online travellers' reviews. Therefore, in order to fill this gap the present study seeks to examine and understand how innovative experience impacts upon travellers' satisfaction and transforms their behavior by analyzing online traveller reviews posted on TripAdvisor.

The specific objectives of this research are presented in the following statements:

- to investigate to what extent the innovative service experiences of visitors affect their subsequent behaviors, attitudes and/or satisfaction;

- to examine if innovative experiences offered to visitors have substantial effects and a positive attitude on their revisit intentions;

- to understand whether innovative experiences can shift visitors' perceptions while impacting on their post-purchase decisions; and

- to explore how visitors are engaged with the innovative service experiences offered by the high-tech hotel they visit.

\section{Literature Review}

\section{The Concept of Innovation in the Hospitality and Tourism Sector}

Different from the concept of invention, innovation is defined as "a new service, product, process or idea" which refers to reapplying or adapting to existent ideas in a unique or peculiar way (Siguaw et al., 2009: 7). The concept of innovation may address the process of change or the outcome of the process stemming from the change, such as a new product, service or organization, or the period of time which designates the result of the process, whilst the process in itself may encapsulate innovation activities (Mattsson et al., 2005). More concretely, the innovation, in essence, possesses three basic components: creativity, a problem-solving approach, and a new way of thinking (Moscardo, 2008).

In the existing literature there are a number of studies dealing with the issue of innovation within a tourism context from a diverse range of perspectives (e.g., Hall, 2009; Jaaron and Backhouse, 2018; Larson, 2009; Thomas, Wood, 2014; Williams, Shaw, 2011). Shumpeter's (2017) analysis of innovation, regarded as one of the main approaches that can also be adapted to the tourism industry, is predominantly referenced (Hjalager, 20o9; Weiermair, 2006). According to Shumpeter's approach an innovation can consist of the following: 1) product innovations, 2) process innovations, 3) marketing innovations, 4) input innovations, and 5) organizational innovations. OECD (2005) has defined four dimensions of an innovation: 1) product innovations, 2) process innovations, 3) organizational innovations, and 4) marketing innovations. 
One of the most salient studies is Hjalager's (2010) innovation approach which presents the following types for the service sector in leisure and hospitality: 1) product or service innovations, 2) process innovations, 3) managerial innovations, 4) management innovations, and 5) institutional innovations. Product or service innovations include those comprised of changed or completely new services or products that can be perceived by the producers, consumers, suppliers or competitors (Hjalager, 2002). Process innovations refer to the factors that are potentially able to increase efficiency, productivity and flow by intensively using existing technology (Hjalager, 1997; Lee et al., 2016). Managerial innovations mostly reflect arrangements and approaches, such as new organizational structures and administrative systems that aim at providing workplace satisfaction while striving to retain staff (Damanpour, Aravind, 2011; Hjalager, 2010). Management innovations include new management styles and the application of new programs which may shift the relationship between tourism providers and customers. Finally, institutional innovations refer to the adaption of new organizational structures (Camisón, Monfort-Mir, 2012; Hjalager, 2010).

On the other hand, Larson (2011) proposed two distinct types of innovation under the heading of institutionalized innovation processes, namely, planned and emergent. According to these approaches, planned innovation work is consciously designed whilst emergent innovation refers to the process in which groups or individuals have the ability to react timely in response to changed circumstances by means of ad hoc decisions. On the other hand, Tajeda and Moreno (2013) described the notions of size, cooperation, capital structure and dependency on tour operators as the main determinants of innovation. According to their approach, the authors claim that these determinants can potentially affect the successful implementation process of innovation for small and medium-size enterprises (SMEs) within the tourism industry.

The easier to use the technology, the more positive the user attitude, which in turn can have a substantial impact on increasing the intention to use it (Lu et al., 2015). It is, therefore, in the present era that customers appear to be more engaged in gaining innovative experiences; thus, they seek tourism destinations and hotel establishments that have been designed to provide their customers with more technology-driven equipment leading to innovative experiences (Pikkemaat, Zehrer, 2016; Su, 2011). As such, it is believed that the successful implementation of innovation within the hospitality and tourism sector can only be achieved by providing successful service innovations (Verma et al., 2008). This kind of innovation is denoted by Hjalager and Nordin (2011) as the "user-driven innovation" which derives and results from external purchasers' expectations and needs, and encompasses several components such as new products, services, concepts, processes, distribution systems, marketing methods, etc. According to the authors, the user-driven innovation can be interchangeably used in the context of customer-driven or customer-centric innovation.

\section{Service Innovation in the Hospitality and Tourism Sector}

It is a commonly held idea that the innovation process related to a product is usually postulated as involving innovation for services which signals the assimilation insight (Gremyr et al., 2014). Considering service innovation in the hotel industry, it may consist of new services, products or processes, along with already existing ideas that can be redesigned or formulated to be used in different ways for a variety of customers (Vila et al., 2012). According to Hjalager (2010), product or service innovations can play a key role as a main determinant factor impacting on customers' purchase decisions, with the highest percentage of such innovation being found in tourism (Aldebert et al., 2011). 
The distinction between product and service innovation can be explained as a difference between an innovation in the manufacturing industry as opposed to one in the services sector (Carlborg et al., 2013). However, in the hospitality and tourism industry either product or service innovation or a combination of both forms can be applied. Hall and Williams (2008) propose four distinctive features of service innovation. These are: the co-terminality of production and consumption, information intensity and the role of IT, quality enhancement and human resources, and the critical role of organizational factors. Each of the proposed domains play a crucial role in generating integral parts in the creation of value for innovation within the service sector. Wang, Voss, Zhao and Wang (2015) put forward a concept of service innovation divided into three strands: business model innovation, service product innovation and service process innovation. The components of this type of service innovation combine all the features mentioned above, which better helps to draw a holistic picture of service innovation.

More recently, the issue of service innovation has been the main research focus of scholars, who have dealt with it from various perspectives (Baradarani, Kilic, 2018; De la Peña et al., 2016; Gaaron, Backhouse, 2018; García-Villaverde et al., 2017; Gürlek, Tuna, 2018; Okoe et al., 2017). Considering the current literature on studies undertaken by scholars relating to service innovation in the hospitality and tourism sector, they are very limited and the majority mainly concentrate on production intensive industries (Souto, 2015; Tajeddini et al., 2017), despite the fact that services are considered to be vital for global and national economies. While innovation for institutional success is of great importance, the issue of service innovation deserves special attention for scholars and industry practitioners (Randhawa et al., 2015). As such, the present study is an attempt to fill this gap in the existing literature.

\section{Methodology}

\section{Data Collection and Data Processing}

In order to meet the research objectives, data was taken from the online reviews of travellers who stayed at the Eccleston Square Hotel, London, which is classified as being one of the top ten high-tech hotels around the world, between June 2014 and September 2017. On examination of the data, a qualitative content analysis was employed that followed three main phases: reducing the data, displaying the data, and drawing and verifying the conclusions (Miles, Huberman, 1994). To provide reliability during the research data analysis process two independent coders were used (Hayes, Krippendorff, 2007).

Before the data analysis process was begun, the online reviews of travellers were transferred from the TripAdvisor site to hard copy. The material was then coded and reduced to raw data. Next, the raw data was divided into meaningful categories upon which both coders had commonly agreed. Afterwards, those codes identifying travellers' main perceptions in relation to their trip were classified into a main theme and sub-themes, from which categories of words emerged. These categories were extracted by considering synonyms referring to the identified generic theme of "experience" and its sub-themes, created under this main theme. Any dissimilarity that emerged during the coding process between the two coders was solved amongst themselves by debating disagreement until a compromise was reached (Xiang, Gretzel, 2010). 


\section{Eccleston Square Hotel as a Case Study}

Eccleston Square Hotel, which is classified as one of the ten most high-tech hotels around the globe, is located five minutes' walk from the Victoria station travel hub and the Gatwick Express in the heart of central London. Integrating the latest technology with sophisticated interiors and quality service, each detail of the Eccleston Square Hotel has been designed to provide its customers with a unique experience, combining both the ultimate in technology with an olde worlde charm, as seen in the historic architecture of the hotel's exterior. Inside the hotel, each guestroom provides the visitor with such high-tech gadgets as keypads to control music and lighting, flat screen television concealed in the bathroom mirror, 46-inch HD ${ }_{3} \mathrm{D}$ Neo plasma TV with surround sound, 3D DVD library, personal in-room electronic-tablet device (e.g., iPad2) which acts as a digital concierge, enabling customers to order room service, arrange a beauty appointment, etc. from the comfort of their room. Furthermore, the Eccleston Square Hotel offers many luxury services, such as electronically adjustable beds (Berman, 2017; Ecclestone Square Hotel London, 2018).

Table 2. Case Selection Criteria

\begin{tabular}{|c|c|}
\hline Case-selecting criteria & Selection of Eccleston Square Hotel \\
\hline Stratified purposeful & $\begin{array}{l}\text { - The hotel selected for the case study possesses certain characteristics which allows an exploration of } \\
\text { the phenomenon being investigated (i.e., the hotel is classified as one of the top ten high-tech hotels } \\
\text { around the world). }\end{array}$ \\
\hline Criteria & $\begin{array}{l}\text { - The selected hotel meets the research criteria as it is classified among the top ten high-tech hotels } \\
\text { around the world, and offers customers a diverse range of innovative service experiences. }\end{array}$ \\
\hline Convenience & $\begin{array}{l}\text { - The researcher has had a chance to access necessary information about the selected hotel from the } \\
\text { well-known internet platform TripAdvisor. }\end{array}$ \\
\hline
\end{tabular}

Source: Veal, (2011: 295)

\section{Results}

After the qualitative content analysis was finalized, which was implemented by two independent human coders following eight different sub-themes (Location, Hotel \& Place, Rooms, Staff, Revisit Intension/Recommendation, Food \& Beverages, Technological Design \& Equipment, Product(s) \& Service(s)) created from the main theme of Experience, categories of words frequently used by travellers in their online reviews and based on codes were extracted from the above-mentioned sub-themes.

\section{Experience}

'Experience' emerged as the most significant theme for travellers visiting the Eccleston Square Hotel, in terms of service innovation experience, and includes such words as: great experience, excellent experience, fabulous experience, memorable hotel experience, lovely experience, perfect experience, pleasant experience, beautiful experience, amazing experience, fantastic experience, exceptional experience, unique experience, fantastic stay, good experience, comfortable stay, excellent stay, pleasant stay, wonderful stay, delightful stay, worth staying, awesome experience, beyond expectation, happy with the experience and fabulous experience. 
Overall, the majority of travellers mentioned their satisfaction, referring to positive experiences, whilst only a few visitors described negative ones: poor experience (1), bad experience (1), not good value for money (1), not happy with the experience (1) and waste of money (1).

One of the most strongly put positive reviews is as follows:

[...] Every member was gracious and exceedingly helpful in making my stay the \#1 most memorable hotel experience I have had in a myriad of experiences travelling domestically and internationally.

Other travellers described their opinions related to the theme of experience in the following ways:

Clean, stylish and modern. This was my second stay at this hotel, and I was again very satisfied with my experience.

Truly a great travel experience.

Taking visitors' reviews into account, it can be seen that their innovative service experiences in a high-tech hotel is reflected in many different ways in several distinct areas.

\section{Location}

In this category, travellers' reviews concerning the location of the hotel were mostly positive. Great, good, excellent, nice, perfect, modern, renovated, calm, quiet, pretty, tranquil, fabulous, lovely, well-located, brilliant, best, ideal, super, fantastic, handy and nice are the words most frequently expressed in their online reviews.

One traveller shared the opinion:

[...] Very well located. Nice and quiet. Good for business and also for family stays. Walking distance from Victoria station. Very convenient if you fly into London from Gatwick.

This shows that travellers often consider the location of the places in which they spend their trip or holiday, which can be seen in the selection of their accommodation. It is also a factor in determining their quality of experience and satisfaction.

\section{Hotel \& Place}

As in the case of location, the sub-theme 'hotel and place' is also seen as a positive element influencing visitors' satisfaction and experience. Those descriptors concerning the innovative experiences of travellers are: well designed, latest technology, high-tech, modern, innovative, beautiful, nice, relaxing, lovely, great, overpriced, perfect, special, little, modern, clean, high standard, wonderful, cool, best, lovely, worth money, smart, one of the best, incredible, elegant, smart, fantastic, fabulous, favourite and friendly atmosphere.

One guest visiting the Eccleston Square Hotel wrote:

Fantastic hotel. Brilliant hotel. We stayed two nights and wish we could've stayed longer. Room was excellent and was finished to a very high standard. Every part of the hotel was spotless.

Another traveller expressed their opinion as follows:

[...] For us, hotels are about sleep and tidy-up between touring and theatre. If you want to be entertained by your room, this place has the bells/whistles in a very clean, high ceiling, elegant environment [...]

In their online reviews visitors assess hotel and place as a key factor influencing their comfort. 


\section{Rooms}

Regarding the innovative service experiences of visitors, rooms are seen as one of the main factors affecting the quality of their stay. Those words describing rooms are: modern, small, tiny, cramped, high-tech, comfortable, amazing, highest quality, functional, well-appointed, well-organized, contemporary, cosy, spotless, nicely decorated, stunning, sleek, funky, immaculate, stylish, fantastic and disappointing.

One guest reviewed their room as follows:

A friendly and cosy boutique hotel near Victoria station. My nice 'cheaper' room overlooking Eccleston Square was pretty small but with a large bed in it. Many high-tech amenities in the room, I just wish there was a writing desk in the room [...]

Another traveller also elaborated on this sub-theme:

Eccleston Hotel situated in a quiet square overlooking a mature and beautiful park has friendly and professional staff. Rooms are very clean, very comfortable and high tech, excellent decor with air con and room service.

\section{Staff}

Overall, the majority of guests visiting the Eccleston Square Hotel agreed that the staff were friendly, good, polite, helpful, lovely, amazing, professional, attentive, competent, courteous, excellent, great, nice, polite, warm, welcoming, wonderful, kind, gentle, gracious and brilliant.

As one satisfied guest wrote:

[...] Always a warm welcome and very clean rooms. The staff really try to make your stay as comfortable as possible [...]

Another guest visiting the hotel wrote:

Everyone that was on staff during my stay was kind, gracious and provided exceptional customer service.

Travellers' opinions and online reviews reveal that the staff constitute one of the most significant assets of a hotel which can impact on the affective and subjective experience of a visitor, even when they stay in high-tech hotels where technological facilities are an integral part of their holiday.

\section{Revisit Intention \& Recommendation}

Concerning this sub-theme, travellers appear to be mostly satisfied, using language such as: will stay here again, visit again, coming back/will return, will book again, highly recommended, a must stay, plan to stay again, would recommend this hotel, go there and enjoy, definitely will return, will repeat, happily stay again, strongly consider staying again, consider staying again and probably stay again. Only a few guests expressed negative comments such as: would not return (3), will never return (3), recommended not to stay (3), probably not again (2), would not stay here again (2) and never stay again (1).

One traveller visiting the hotel expressed their revisit intention and recommendation as follows:

I recommend the Signature King and I found the continental breakfast filling. I will strongly consider staying here again if I should return to London [...]

It can be concluded from the above statement that visiting a high-tech hotel can have a positive influence on revisit intention and post-purchase decisions (Ukpabi et al., 2018). 


\section{Food \& Beverages}

The words mostly identified with this sub-theme are: delicious, good, tasty, fresh, plentiful, nice, great, great quality, good quality, excellent, superb, amazing, the best, fabulous, lovely, genuinely good, high standard, great quality, fine, tasty, poor, undrinkable and disappointing.

One of the visitors wrote:

[...] Since I last stayed, they opened a new restaurant, serving small plates. It was one of the best meals I had on a three-week trip to Italy and England: perfectly cooked lamb chop with grilled petite tomatoes and pieces of eggplant and a very tasty plate of mashed potatoes with truffle oil. The wait-staff were pressed with a large party in back and several tables in front, but were helpful and observant and flexible.

Food and beverages are regarded as another key determinant of the innovative service experiences of visitors, and many expressed their satisfaction by recommending them to other travellers in their online reviews. Overall, this sub-theme can be considered as an auxiliary service encapsulating several different dimensions and playing a significant role in the creation of added value to travellers' experiences.

\section{Technological Design \& Equipment}

Technological design and equipment constitutes one of the key drivers of innovative experience for travellers visiting high-tech hotels. The descriptors predominantly used by travellers of the Eccleston Square Hotel are: the latest, best, high-tech, great, good, smart, tech style, convenient, very hi tech, lots of tech, very cool, high-tech conveniences, good, fabulous, very posh, nice, neat, up to date, modern, sleek, flashy, modern tech, best technical equipment, high standard, very well equipped, classy, useful, unique, awesome, stylish, excellent, super, impressive, incredible and priceless.

One guest shared their view about technological design and equipment:

My experience with high-tech hotels to date is that the technology replaces some of the more traditional expectations we might have as hotel guests [...]

It can be understood from this comment that smart equipment designed along high-tech lines can potentially create an added incentive for visitors and, moreover, change some of their ideas towards more traditional services.

Other travellers stated:

[...] The room was fantastic. It was very modern and full of interesting technology [...]

[...] Super comfy bed - vital. Clean and beautifully decorated. Modern decor and furnishings. Incredible technology throughout, from the lights to the curtains, the shower and the in-room $i$ Pad for ordering room service (which was also excellent) and even a smart phone (didn't use this). This hotel has it all.

The technological design and equipment of the hotel was mostly seen by visitors in a positive way and, thus, increased satisfaction levels. Visitors largely expressed their emotional response to this area in terms of it being a key influence in their overall experience.

\section{Product(s) \& Service(s)}

The sub-theme of products and services is another integral component of visitors' innovative experiences. Overall, visitors' online reviews were positive and expressed as: top-quality, updated, impeccable service, fantastic service, first class service, top quality, good quality, sub- 
urb room service, great service, friendly service, efficient service, good service, great amenities, extraordinary customer service, the best service, incredible service, great facilities, wonderful service, modern amenities, poor room service, lack of customer service, poor customer service and bad service.

One traveller who visited the Eccleston Square Hotel expressed the view:

[...] Room service is superb, especially the breakfasts (best pancakes I have ever had).

Another tourist shared:

The dining area and bar are small but very elegant. The restaurant serves breakfast, lunch and dinner and the bar is well stocked [...]

From the above, it is clear that travellers' opinions of their stay at the high-tech Eccleston Square Hotel in London are mostly positive for each sub-theme of innovative service experiences.

\section{Discussion and Conclusion}

This qualitative case study has attempted to analyze and examine the impact of innovative service experiences on guests visiting the Eccleston Square Hotel in London. Overall, the results based on travellers' experiences have revealed Location, Hotel E Place, Rooms, Staff, Revisit Intention and Recommendation, Food E Beverages, Technological Design E Equipment and Products $\mathcal{E}$ Services as sub-themes, under the main theme Experience, all of which are integral parts of the innovative service experiences of travellers staying at a high-tech hotel in London. The findings of this study have both managerial and theoretical implications, and contribute to the current literature on innovative service experiences within the hospitality and tourism industry.

First, based on the study findings, the innovative service experiences of travellers can be mostly classified as planned innovations rather than emergent ones (Larson, 2011), and mainly fall into the category of the service and product innovations of Hjalager's (2010) innovation approach in tourism. Further, this kind of innovative service experience provided by high-tech hotels can be assessed as a "user-driven" or "customer-centric" innovation (Hjalager, Nordin, 2011), as they are developed by hotel establishments to improve the quality of travellers' experiences.

Second, the results derived from the analysis of travellers' reviews, who visited the hightech Eccleston Square Hotel in London, have demonstrated that customers' responses and reactions to innovative service experiences are manifold and multifaceted (i.e., restorative, sensory, transformative, cognitive, physical and emotional) (Packer, Ballantyne, 2016). From this perspective, it can also be suggested by the findings that offering innovation in smart and high-tech hotels is able to transform traditional expectations into innovative ones, whilst at the same time improving the quality of visitors' service experiences. When considering the online reviews of travellers visiting the Eccleston Square Hotel, London, service innovation experiences can be characterized, overall, as positive and, thus, are a good indication of increased traveller satisfaction during their stay in a high-tech hotel.

Findings from this research show that the innovative service experiences of tourists/travellers/visitors positively affect their subsequent behaviors, to a large extent, and post-purchase attitudes in terms of their revisit intentions to high-tech hotels. More concretely, such experiences can have a substantial shift on travellers' perceptions while impacting on their post-purchase decisions. It has also been found that the majority of online traveller reviews included 
positive experiences and eWOM behaviors, whilst only a few travellers reflected their experiences as being negative ones (Zhang et al., 2017). Results of this study also support the idea that service innovation has important effects on both behavioral intention and travellers' experiences. Such findings comply with results stemming from prior research studies $(\mathrm{Su}, 2011)$.

One of the key findings of this research is that high-tech hotels can provide more heterogeneous and multidimensional characteristics, in terms of experiences regarding service innovation, resulting in the emergence of different behavioral patterns with which the traditional expectations of travellers can be transformed by the more technology-oriented experiences offered by high-tech hotels. Linked to this argument, the findings demonstrate that high-tech hotels can offer innovative experiences to travellers which positively impact on their behavioral intentions. Further, it can be claimed that innovative services and products can potentially drive and improve the quality of travellers' experiences. Moreover, from the point of view of managerial implication, the results of this paper have shown that the innovative services of high-tech hotels can also provide travellers with memorable and meaningful experiences, based on the tangible and intangible components of products and services offered to them (Wan, 2018).

More concretely, it can be concluded that the results indicate and support the view that the transformative power of technologies not only affects tourism actors (Sigala, 2018) but also travellers' attitudes and behavior in the selection of holiday destinations and their intentions to (re)visit technology-driven hotels, which can be identified as a key characteristic of the use of ICTs within the hospitality and tourism industry. It has also been found that high-tech hotels can potentially influence travellers' sense of place, as the results of the research have confirmed. Findings also clearly support the fact that the use of ICT application offered by high-tech hotels is of value to customers by redesigning and differentiating products and services (Ruiz-Molina et al., 2014).

This research paper has utilized the UGC of a single case study, the results of which cannot provide a generalized application to the experiences of travellers towards high-tech hotels; this is the main limitation of this paper. Therefore, by employing a qualitative or quantitative approach, future research can be undertaken to investigate to what extent travellers are willing to pay more for staying in high-tech hotels offering innovative services and products, and can these high-tech hotels potentially turn a short stay into a longer one. How far high-tech or smart hotels are aware of visitors who are ecologically or environmentally conscious, is another area waiting to be explored.

\section{References}

Aldebert, B., Dang, R. J., Longhi, C. 2011. Innovation in the tourism industry: The case of Tourism@. Tourism Management 32(5), 1204-1213.

Baradarani, S., Kilic, H. 2018. Service innovation in the hotel industry: culture, behavior, performance. The Service Industries Journal 38(13-14), 897-924.

Berman, J. 2017. Top Ten High-Tech Hotels Around The World. Retrieved from https:// www.smartmeetings.com/technology/96753/top-10-high-tech-hotels-world, accessed 16.02.2018.

Bilgihan, A., Nejad, M. 2015. Innovation in Hospitality and Tourism Industries. Journal of Hospitality and Tourism Technology 6(3).

Buhalis, D., Licata M.C. 2002. The Future of Tourism. Tourism Management 23(3), 207-220. 
Buhalis, D., Law, R. 2008. Progress in information technology and tourism management: 20 years on and 10 years after the Internet-The state of Tourism research. Tourism Management 29(4), 609-623.

Camisón, C., Monfort - Mir, V. M. 2012. Measuring innovation in tourism from the Schumpeterian and the dynamic-capabilities perspectives. Tourism Management 33(4), 776-789.

Carlborg, P., Kindström, D., Kowalkowski, C. 2013. The Evolution of Service Innovation Research: A Critical Review and Synthesis. The Service Industrial Journal 34(5), 373-398.

De la Peña, M. R., Núñez-Serrano, J. A., Turrión, J., Velázquez, F. J. 2016. Are innovations relevant for consumers in the hospitality industry? A hedonic approach for Cuban hotels. Tourism Management 55, 184-196.

Damanpour, F., Aravind, D. 2012. Managerial innovation: Conceptions, processes, and antecedents. Management and Organization Review 8(2), 423-454.

Ecclestone Square Hotel London. 2018. Retrieved from https://www.ecclestonsquarehotel. com/, (accessed 16.02.2018).

García- Villaverde, P. M., Elche, D., Martínez-Pérez, Á., Ruiz-Ortega, M. J. 2017. Determinants of radical innovation in clustered firms of the hospitality and tourism industry. International Journal of Hospitality Management 61, 45-58.

Gürlek, M., Tuna, M. 2018. Reinforcing competitive advantage through green organizational culture and green innovation. The Service Industries Journal 38(7-8), 467-491.

Gremyr, I., Witell, L., Löfberg, N., Edvardsson, B., Fundin, A. 2014. Understanding New Service Development and Service Innovation through Innovation Modes. Journal of Business \& Industrial Marketing 29(2), 123-131.

Hall, M.C., Williams, A.M. 2008. Tourism and Innovation. Routledge, Abingdon.

Hall, C. M. 2009. Innovation and tourism policy in Australia and New Zealand: never the twain shall meet?. Journal of Policy Research in Tourism, Leisure and Events 1(1), 2-18.

Hayes, A.F., Krippendorff, K. 2007. Answering the Call for a Standard Reliability Measure for Coding Data. Communication Methods and Measures 1(1), 77-89.

Hjalager, A.M. 1997. Innovation patterns in sustainable tourism. Tourism Management 18(1), 35-41.

Hjalager, A.M. 2002. Repairing innovation defectiveness in tourism. Tourism Management, 23(5), 465-474.

Hjalager, A. M. 2009. Cultural tourism innovation systems-the Roskilde festival. Scandinavian Journal of Hospitality and Tourism 9 (2-3), 266-287.

Hjalager, A.M. 2010. A review of innovation research in tourism. Tourism Management 31(1), $1-12$.

Hjalager, A. M., Nordin, S. 2011. User-driven innovation in tourism-A review of methodologies. Journal of Quality Assurance in Hospitality \& Tourism 12(4), 289-315.

Jaaron, A. A., Backhouse, C. J. 2018. Operationalisation of service innovation: a systems thinking approach. The Service Industries Journal 38(9-10), 561-583.

Ip, C., Leung, R., Law, R. 2011. Progress and development of information and communication technologies in hospitality. International Journal of Contemporary Hospitality Management 23(4), 533-551.

Miles, B.M., Huberman, A.M. 1994. Qualitative Data Analysis (2nd Edition). Sage Publications, USA.

Larson, M. 2009. Festival Innovation: Complex and Dynamic Network Interaction. Scandinavian Journal of Hospitality and Tourism 9(2-3), 288-307. 
Larson, M. 2011. Innovation and creativity in festival organizations. Journal of Hospitality Marketing \& Management 20(3-4), 287-310.

Law, R., Buhalis, D., Cobanoglu, C. 2014. Progress on information and communication technologies in hospitality and tourism. International Journal of Contemporary Hospitality Management 26(5), 727-750.

Lee, C., Sardeshmukh, S. R., Hallak, R. 2016. A qualitative study of innovation in the restaurant industry", Anatolia 27(3), 367-376.

Leung, R., Law, R. 2007. Information technology publications in leading tourism journals: A study of 1985 to 2004. Information Technology \& Tourism 9(2), 133-144.

Leung, D., Law, R., Van Hoof, H., Buhalis, D. 2013. Social media in tourism and hospitality: A literature review. Journal of Travel \& Tourism Marketing 30(1-2), 3-22.

Mattsson, J., Sundbo, J., Fussing-Jensen, C. 2005. Innovation systems in tourism: The roles of attractors and scene-takers. Industry and Innovation 12(3), 357-381.

Moscardo, G. 2009. Sustainable tourism innovation: Challenging basic assumptions. Tourism and Hospitality Research 8 (1), 4-13.

Nieves, J., Quintana, A., Osorio, J. 2014. Knowledge-based resources and innovation in the hotel industry. International Journal of Hospitality Management 38, 65-73.

OECD. 2005. The Measurement of Scientific and Technological Activities: Guidelines for Collecting and Interpreting Innovation Data. Oslo Manual (3rd Edition), OECD, Paris, France.

Okoe, A. F., Boateng, H., Narteh, B., Boakye, R. O. 2018. Examining human resource practice outcomes and service innovation. The Service Industries Journal 38(7-8), 431-445.

Packer, J., Ballantyne, R. 2016. Conceptualizing the Visitor Experience: A Review of Literature and Development of a Multifaceted Model. Visitor Studies, 19(2), 128-143.

Peters, M., Pikkemaat, B. 2006. Innovation in tourism. Journal of Quality Assurance in Hospitality \& Tourism 6(3-4), 1-6.

Pikkemaat, B., Zehrer, A. 2016. Innovation and service experiences in small tourism family firms. International Journal of Culture, Tourism and Hospitality Research 10(4), 343-360.

Randhawa, P., Kim, M., Voorhees, C. M., Cichy, R. F., Koenigsfeld, J. P., Perdue, J. 2016. Hospitality service innovations in private clubs. Cornell Hospitality Quarterly 57(1), 93-110.

Ruiz-Molina, M. E., Gil-Saura, I., Berenguer-Contrí, G. 2014. Information and communication technology as a differentiation tool in restaurants. Journal of Foodservice Business Research 17(5), 410-428.

Sigala, M. 2018. New Technologies in Tourism: From multi-disciplinary to anti-disciplinary advances and trajectories. Tourism Management Perspectives 25, 151-155.

Siguaw, J., Enz, C. A., Kimes, S. E., Verma, R., Walsh, K. 2009. Cases in innovative practices in hospitality and related services: Set 1 [Electronic article], Cornell Hospitality Report, 9(17), 6-31, Retrieved from https://scholarship.sha.cornell.edu/, (accessed 22.02.2018).

Shumpeter, J. A. 2017. The Theory of Economic Development. Routledge, Abingdon.

Souto, J. E. 2015. Business model innovation and business concept innovation as the context of incremental innovation and radical innovation. Tourism Management 51, 142-155.

$\mathrm{Su}, \mathrm{C}$. S. 2011. The role of service innovation and customer experience in ethnic restaurants. The Service Industries Journal 31(3), 425-440.

Tejada, P., Moreno, P. 2013. Patterns of innovation in tourism 'small and medium-size enterprises. The Service Industries Journal 33(7-8), 749-758.

Tajeddini, K., Altinay, L., Ratten, V. 2017. Service innovativeness and the structuring of organizations: The moderating roles of learning orientation and inter-functional coordination. International Journal of Hospitality Management 65, 100-114. 
Thomas, R., Wood, E. 2014. Innovation in tourism: Re-conceptualising and measuring the absorptive capacity of the hotel sector. Tourism Management, 45, 39-48.

Ukpabi, D., Olaleye, S., Mogaji, E., Karjaluoto, H. 2018. Insights into Online Reviews of Hotel Service Attributes: A Cross-National Study of Selected Countries in Africa. In: Information and Communication Technologies in Tourism 2018 (pp. 243-256). Springer, Cham.

Veal, A.J. 2011. Research Methods for Leisure and Tourism: A Practical Guide. Pearson Education Limited, England.

Verma, R., Anderson, C., Dixon, M., Enz, C., Thompson, G., Victorino, L. 20o8. Key elements in service innovation: Insights for the hospitality industry [Electronic article], Cornell Hospitality Roundtable Proceedings 1(1), 6-12, Retrieved from https://scholarship.sha.cornell. edu/, (accessed 22.02.2018).

Vila, M., Enz, C., Costa, G. 2012. Innovative practices in the Spanish hotel industry. Cornell Hospitality Quarterly, 53(1), 75-85.

Wan, C. B. 2018. Flourishing Through Smart Tourism: Experience Patterns for Co-Designing Technology-Mediated Traveller Experiences. The Design Journal 21(1), 163-172.

Wang, Q., Voss, C., Zhao, X., Wang, Z. 2015. Modes of service innovation: a typology. Industrial Management \& Data Systems 115(7), 1358-1382.

Wang, D., Xiang, Z., Fesenmaier, D.R. 2016. Smartphone Use in Everyday Life and Travel. Journal of Travel Research 55(1) 52-63.

Weiermair. K. 2006. Prospects for Innovation in tourism. Journal of Quality Assurance in Hospitality \& Tourism 6(3-4), 59-72.

Williams, A. M., Shaw, G. 2011. Internationalization and innovation in tourism. Annals of Tourism Research 38(1), 27-51.

Xiang, Z., Gretzel, U. 2010. Role of Social Media in Online Travel Information Search. Tourism Management 31(2), 179-188.

Zhang, T.C., Omran, B.A., Cobanoglu, C. 2017. Generation Y's positive and negative eWOM: use of social media and mobile technology. International Journal of Contemporary Hospitality Management 29(2), 732-761. 